\title{
Prospects of Effective Management of Dementia for Ukraine: Learning from International Experience
}

\author{
Oleksandra KHUDOBA \\ Lviv Regional Institute for Public Administration \\ The National Academy for Public Administration under the President of Ukraine \\ lesia.khudoba@gmail.com
}

\begin{abstract}
Despite the scale of the spread and economic impact of dementia on families, caregivers and the community as a whole, the disease of dementia is either not discussed at all or is not a priority in low-economic countries. The purpose of this study is to attract attention of policy and decision makers to dementia problems in Ukraine to facilitate developing systems of health care and social care for people living with dementia and their caregivers. It is one of the first attempts to look at the problem of dementia in Ukraine from the public administration point of view in different aspects and directions, as well as an attempt to initiate a professional discussion with policy and decision makers on issues of developing and implementing a strategy for people living with dementia and their families. Since Ukraine is not yet on the list of the countries which joined the global program of counteracting dementia and this problem is not relevant to Ukraine, we tried to make a short comparative analysis of Ukraine with countries for which dementia is one of the national priorities (France, the Netherlands, the USA, the UK, Norway and Australia).
\end{abstract}

Keywords: mental health; health policy; disease prevention; organisation of health care; health statistics;

JEL Classification: H51; H75;

\section{Introduction}

The rapid aging of the population against the background of increase of longevity affects the formation of economic processes and creates an additional load on both the health care system and the social system. To remain effective and address, in timely fashion, the needs of elderly people, these systems must adapt to the needs of citizens, provide for new services and implement them into institutions' activities. The management of medical care for the elderly in many issues requires coordinated actions between these systems and, accordingly, requires additional research. The case analysis and development of recommendations should be carried out for each country separately, taking into account its specificity and capabilities.

Along with the significant increase in the number of elderly people, a new problem of public health - the spread of dementia - is acute. This is a condition in which a person cannot understand his own abilities, is not able to cope with everyday life difficulties and increasingly becomes a burden both for the family and society. According to various estimates, from 58\% (Alzheimer's Disease International, 2015), 60\% (World Health Organization, 2015a) to 66\% (Skladzien et al., 2011; Brodaty and Donkin, 2009) of people with dementia live in low and middle-income countries, and this percentage is expected to increase over the next few years. A rise in incidence in older age groups in developing countries can further increase the inequality in access to medical and social services both between countries and among different age groups within countries. 
The mental health of the population is an important component of public health, which hinges on the well-being of the population, the stability and development of all spheres, and hence the capacity of each country. Ukrainian researchers state that about $30 \%$ of people in Ukraine suffer from mental disorders throughout their lives, and most people (up to $75 \%$ ) with common mental disorders in Ukraine have no chance to receive quality and professional assistance. The main reasons limiting access to this type of care in Ukraine are connected to the lack of public confidence in the health care system due to inefficiency, and sometimes the harmfulness of services. Stigmatization of this population group and sense of shame, low awareness of the population, geographical distance from the place of professional assistance, distortion of information on treatment approaches and high cost of treatment worsen the situation even more (World Bank Group, 2017).

It is the environment in which citizens reside that can either contribute to the preservation and improvement of health, or vice versa, create the preconditions for its deterioration. Accordingly, the use or non-use of the necessary social resources or economic incentives can have different medical consequences for countries with different levels of economic development. Some high-income countries carry out large-scale campaigns to increase demographic awareness of the population as far as various dementia issues are concerned, but efforts in this area need to be strengthened first and foremost at the global level. Despite the scale of the spread and economic impact of dementia on the family, on caregivers and on the community as a whole, the disease is either not discussed at all or is not a high priority in low-economic countries (World Health Organization, 2012).

Over time, countries that will face the need for effective policy formation and plan to implement dementia measures will face a number of specific obstacles that they will have to overcome. Since many factors affecting the processes of maintaining good mental health or mechanisms of inclusion of people with mental disabilities in the society are beyond the scope of the health-care system, they cannot be relied upon solely from this system. Hence, effecting a response to dementia requires coordinated and concerted actions of various spheres in both the state and non-governmental sectors. All things considered, a good resource is studying the experience of countries that have embarked on their path to counter dementia and are determined to succeed in combating this disease.

\section{How Approaches to Programming and Decision-Making are Defined}

\subsection{Features of approaches to forming a dementia policy globally}

Changes in the approaches of governments in the struggle to increase the duration and improvement of living standards throughout the life period requires reviewing the priorities of the country's national health policy. These changes are already perceptible at the global level and are introduced gradually into national policies of countries.

The strategic program of Millennium Development Goals, which was valid / active up to 2015 and agreed upon by all countries of the world and all leading world institutions for development, was aimed only at reducing infant mortality (children under 5 years of age) and improving maternal health, as well as on counteraction to malaria and HIV / AIDS. However, swelling of numbers of non-communicable diseases that has reached epidemic proportion, especially in countries with low economic development, has prompted 
governments to make significant changes to the next World Program - Sustainable Development Goals (The United Nations, 2018). The absolutely new for this program approach, reflecting the integration of health policies in different areas, aims at improving the health of all groups in all ages without neglecting the most vulnerable and least protected people in the elderly population strata.

The issues of counteracting dementia are relatively new in the agenda for the formation of national priorities, and accordingly there is still insufficient experience with regard to the effectiveness of the measures proposed by the WHO (Wortmann, 2013). Since life expectancy is predicted to grow in all countries, more and more politicians are interested in how to influence the health of the population and how to reduce the socioeconomic impact of dementia that can be considered as one of the biggest challenges of the 21st century (Holtzman et al., 2011; University of Cambridge, 2018).

Mental and neurological diseases, according to the WHO experts (World Health Organization, 2012) have low priority in society and are often given insufficient attention in the formation of national policies. According to the WHO Mental Health atlas, $60 \%$ of countries pursue a focused mental health policy and $71 \%$ of countries have a mental health plan (World Health Organization, 2017a). In most of these countries, specific provisions have been developed to help people with dementia.

Contrary to popular belief, dementia is not a natural or inevitable consequence of aging, but this condition worsens the functions of memory, speech, perception and thinking, significantly interfering with the ability to support the activities of everyday life. Therefore, monitoring the national plans of countries that have become leaders in countering dementia can be useful for both developed and developing countries. It is expected that this issue may be most "painful" for developing countries: according to experts, the number of elderly people aged 65 and older will have been increased by $140 \%$ by 2030 in developing countries, while in developed countries this figure will have reached 51\% (Dobriansky et al., 2007).

The development and implementation of specific policies and plans for mental health care are essential components of good governance, allowing for predicting and evaluating future actions. Mental health policy, consistent with international approaches and national obligations, includes a set of values, principles and objectives for improving mental health and reducing the burden of mental disorders in the population (World Health Organization, 2017a).

Mental health policy is a part of the national health policy and is seen as a formal statement or procedure within the government defining goals, priorities and parameters of action in response to health needs in the context of available resources (World Health Organization, 2004). In fact, together with its national plan, the policy reflects the country's actual vision of political directions and strategies for ensuring public health (World Health Organization, 2018).

A mental health plan is a detailed scheme of actions that usually involves defining the principles of the strategy and setting terms and requirements for resources aimed at maintaining mental health; a detailed scheme for the implementation of strategic activities aimed at promoting mental health, the prevention of mental disorders, treatment and rehabilitation. This plan allows to realize the vision, values, principles and goals defined in the policy. In the context of counteraction dementia, development of the national plan can be equal to the recognition of the problem by the government. The plan should clearly indicate the need for changes in national health policy and the need for the care and 
treatment of people suffering from dementia as well as focus on the importance to provide comprehensive support to their caregivers.

Depending on the level of development of public activity and the political will of authorities at both national and regional levels, these plans may differ significantly in their origin. Some of them are developed by key state institutions independently while some are developed by public organizations, which represent the interests of patients with dementia as well as further advocate consideration and implementation of these plans. However, most plans are the joint work of the state and national public associations, based on partnership between the government and non-governmental interested organizations (Rosow et al.., 2011).

Alzheimer's disease and other dementia is a global health problem, and it is an exceptional size, affecting the increase in costs and social changes in society. The personal, social and economic consequences of dementia are enormous, which leads to the increase in the costs of long-term care to governments, communities, families and individuals and the loss of productivity for economies. As the National Response Plan of Alzheimer's disease and other dementia is the single most powerful tool for improving the care and support of dementia in any country, the WHO recommends each country to develop the national plan, creating a framework for strategic actions at different levels of management (Pot and Petrea, 2013).

The most common types of dementia are Alzheimer's disease and vascular dementia, and, according to the WHO recommendations, priority actions in national plans should include increasing awareness of dementia and its risk factors (basically connected with cardiovascular system disorders), building capacity for timely diagnosis, loyalty to goodquality permanent care and services, staff training and research (World Health Organization, 2017b).

\subsection{Features of approaches to forming a dementia policy at the national levels}

The world experience shows that democratic institutions can influence the society's development in various ways, including influencing public health. Differences in health policy and the results obtained from implementing this policy do not always depend solely on the economic state of a particular country. Often countries with a similar level of economic development can have radically different levels of development of the health system and public health.

The health system policy of each country is formed under the influence of various incentives and factors (for example, national values, the technical and administrative ability of the state, the level of corruption, the power of political guides and the style of its governance), and also depends on the depth and scale of public opinion. This situation requires additional detailed analysis to better understand global health inequalities (Ruger, 2005).

To strengthen the effectiveness of national events, governments need evidence-based and scientifically based facts that can raise public awareness and influence the shaping of policies in appropriate areas. This scientific foundation must address the problem in a comprehensive way, involving scientists from different sectors (such as medicine, social work or public administration), developing the interdisciplinary approach. The research results of studying the problems at the local level and foreign experience can form the basis of national plans or accelerate their development. 
Stigma, rejection by society and inadequate financial resources remain the main obstacles to proper treatment and care for people with dementia. In response to the growing needs of people with dementia and their families and guardians of the Alzheimer's Association (advocacy groups for people with dementia and their caregivers), politicians, governments, health professionals and other stakeholders began to look for alternative ways to address this problem.

At least 19 countries, including Australia, France, Norway, the United Kingdom, Italy and the United States began to offer their national policies and plans to stop the progression of the disease, provide proper care and treatment for dementia patients, support caregivers, and implement prevention strategies for individuals with an increased risk of the disease (World Health Organization, 2016).

International organizations make great efforts to draw attention to the problems of dementia and reduce the severity of this disease for future generations. The list of countries studying the issue of dementia in detail and join the global program of counteracting dementia grows steadily. Since Ukraine is not yet on this list and the problem of dementia is not relevant to it, we tried to make the short comparative analysis of Ukraine with countries for which dementia is one of the national priorities (France, the Netherlands, the USA, the UK, Norway and Australia).

Information on the causes of death is mainly used by medical practitioners to improve patient management tactics, to study the impact of co-morbidities, and to prevent complications in a group of other patients with a similar group of diseases. The set of acquired knowledge is also displayed in the recommendations of national prevention programs. The cause of death can be more established accurately in the case of acute diseases, and, conversely, with chronic diseases, the main cause of death can be masked by other chronic pathologies. Especially it is difficult to find out from the elderly.

In the world ranking of countries, Ukraine occupies the 176th position in terms of death rate from Alzheimer's disease/ dementia. At first glance, it does not cause anxiety and looks favourably enough (Figure 1). In the overall structure of mortality of the Ukrainian population, the same indicator (death from Alzheimer's disease/ dementia) is only $0.38 \%$ (Figure 2).

Figure 1. The positions of countries in the world ranking according to the $\mathbf{5 0}$ top causes of mortality

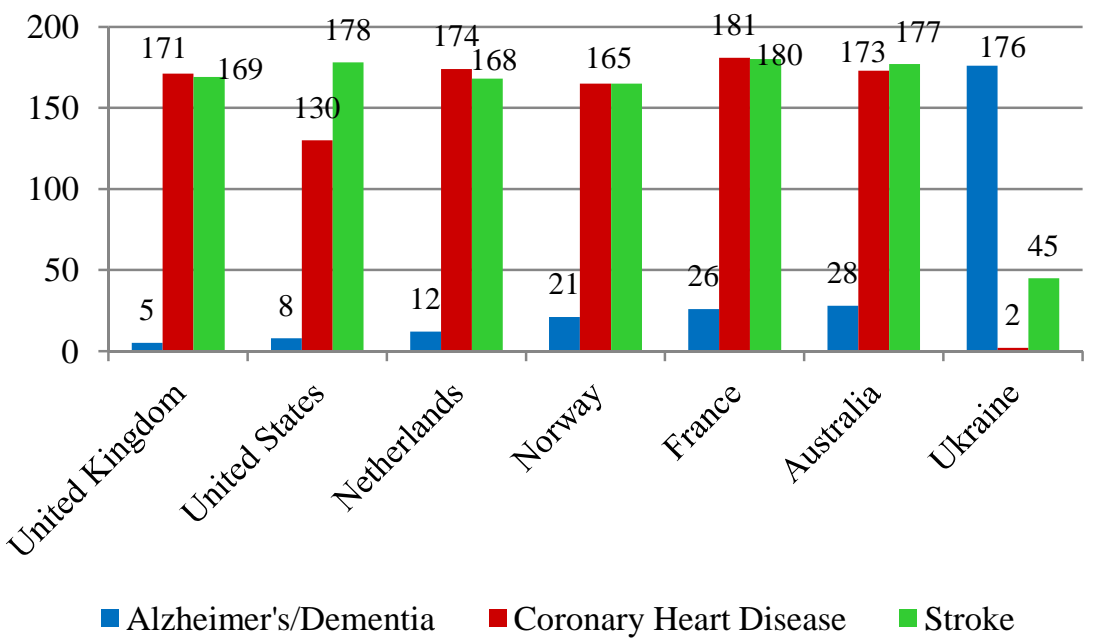

Source: World Life Expectancy (2018) 
Hence from the position of health managers there is no reason to consider the spread of dementia as a national problem. Given the status of the country, as developing and limited resources of the health system, the above mentioned indicators are not grounds for the development of medical and social services for the group of people suffering from dementia to be set as a priority for the government.

\section{Figure 2. Percentage of mortality by indicators in the general structure of mortality}

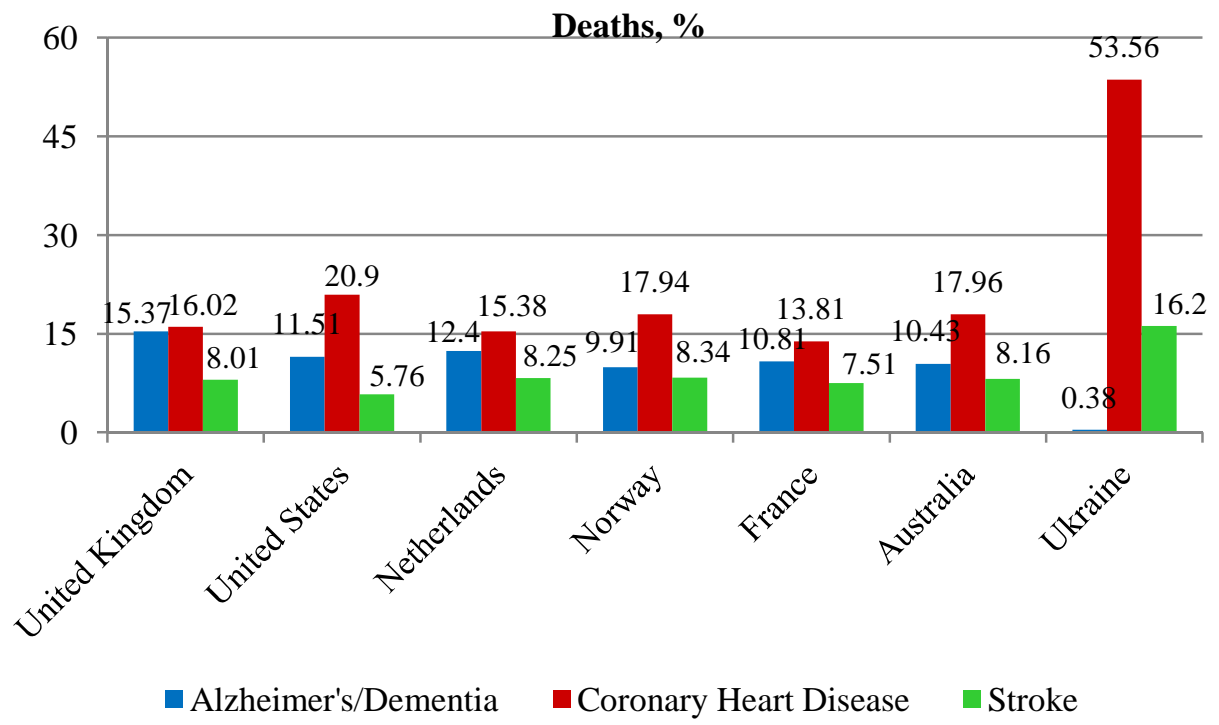

Source: World Life Expectancy (2018)

However, as we see in Figures 1 and 2, in the developed countries, the trend towards the same indicators is completely opposite: all six of our selected countries in the world ranking on death rate from Alzheimer's / dementia fall into the first 30 top positions, and in the national ranking of mortality, this indicator ranges from $9.91 \%$ (Norway) to $15.37 \%$ (United Kingdom) (World Life Expectancy, 2018).

The main causes of death in people with dementia are diseases of the cardiovascular system. Evidence suggests that the risk of certain types of dementia can be reduced by reducing the risk factors for cardiovascular disease. Stroke, as well as ischemic heart disease, can cause excessive risk in people with vascular and mixed dementia (Garcia Ptacek et al., 2016). And just the second difference between Ukraine and the developed countries is that the mortality from coronary heart disease and strokes leads Ukraine to the second and forty-fifth positions respectively in the world, leaving the countries chosen far behind us. The statistics data concerning Ukraine and France is particularly clear and diametrically opposite, according to the indicators analyzed above.

Taking into account the morbidity indicators among the population of the older age groups (Figure 3), psychic disorders occupy the penultimate place in the overall morbidity structure, leaving behind only blood diseases (185.7 per 100,000 of the relevant population). The fact that the incidence of diseases of the circulatory system occupies up to $19 \%$ of the total morbidity structure (Figure 3), and the mortality rate - almost 54\% (Figure 2) leads us to believe that dementia can also be "hidden" in this indicator. The reason for this may be that small numbers of people actually address medical institutions for help and, accordingly, a low level of diagnosis of dementia exists. 
Figure 3. The indicators of morbidity by major classes of diseases among the population of Ukraine of older age groups in 2016 (per 100 thousand of the population concerned)

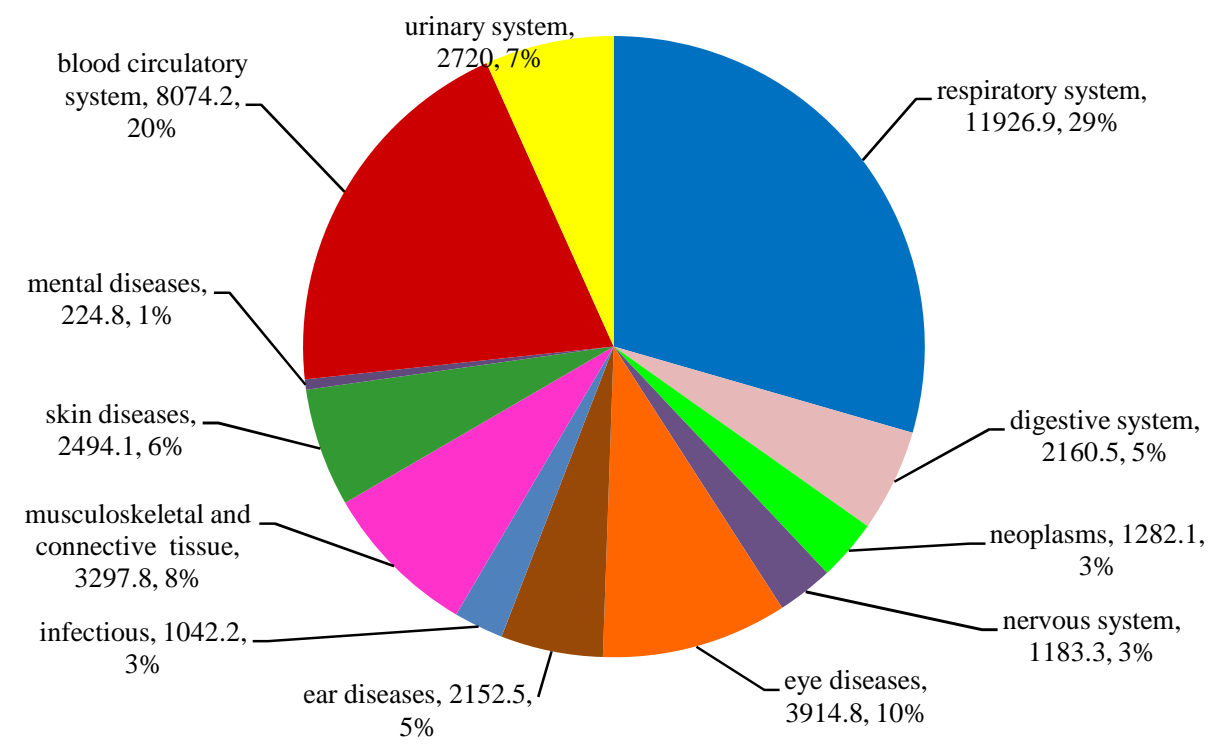

Source: Ministry of Healthcare of Ukraine (2017)

The following data can also confirm our hypothesis. By 2010, Ukraine had been most similar to United Kingdom and France by the population size, which in quantitative terms was expressed as approximately 1: 1.5: 1.5 (Table 1).

Table 1. Profiles of countries in the context of developing a dementia problem as a national priority

\begin{tabular}{|c|c|c|c|c|c|c|c|}
\hline & $\begin{array}{l}\text { United } \\
\text { Kingdom }\end{array}$ & $\begin{array}{l}\text { United } \\
\text { States }\end{array}$ & Netherlands & Norway & France & Australia & Ukraine \\
\hline Population & $61,899,000$ & $309,640,000$ & $16,653,000$ & $4,857,000$ & $62,634,000$ & $21,511,000$ & $45,436,000$ \\
\hline $\begin{array}{l}\text { National } \\
\text { actions }\end{array}$ & $\begin{array}{c}\text { National } \\
\text { Plan 2009- } \\
2014\end{array}$ & $\begin{array}{c}\text { National } \\
\text { Plan 2012- } \\
2015\end{array}$ & $\begin{array}{c}\text { National Plan } \\
\text { 2004-2008 }\end{array}$ & $\begin{array}{c}\text { National } \\
\text { Plan } \\
2011- \\
2012\end{array}$ & $\begin{array}{c}\text { National } \\
\text { Plan 2008- } \\
2013\end{array}$ & $\begin{array}{c}\text { National } \\
\text { Plan 2006- } \\
2010\end{array}$ & - \\
\hline $\begin{array}{l}\text { Fund } \\
\text { allocation }\end{array}$ & $\begin{array}{c}£ 150 \\
\text { million for } \\
\text { two years }\end{array}$ & $\begin{array}{l}\text { information } \\
\text { is not } \\
\text { available }\end{array}$ & $€ 2,4$ million & $\begin{array}{c}1,1 \\
\text { billion } \\
\text { krones }\end{array}$ & $\begin{array}{c}€ 1,6 \\
\text { billion }\end{array}$ & $\begin{array}{l}\$ 2,3 \text { billion } \\
\text { annually }\end{array}$ & - \\
\hline
\end{tabular}

Sources: Rosow et al. (2011), Pot and Petrea (2013)

As of 2017, the number of deaths from Alzheimer's / dementia in Ukraine, France and the United Kingdom in absolute numbers was 2,463: 49,233: 72,375 or 1: 20: 30 , respectively. According to European epidemiological studies, 6 - 7\% of people over 65 years of age have dementia (Pinchyk et al., 2014). Based on these data, and given that the proportion of people over 66 years of age according to different data may reach 20-23\% of the total population in Ukraine, we can only assume that the number of dementia patients in Ukraine is at least 200,000. In our opinion, the confirmation or refutation of this hypothesis is a valid argument for further research. 


\section{Strengthening Coordination and Research to Raise Awareness of Dementia}

The policy of mental health has been focused traditionally on providing medical care to patients with severe forms of mental disease. However, those mental disorders that were widespread, but relatively manageable and related to "small mental disorders" (Nolan and Badger, 2002), which (from the standpoint of medicine) in most cases can be attributed to dementia, were neglected. However, the duration of the disease, the economic consequences of dementia for the patient's family, the social exclusion of the patient, and the psychological burden of the caregivers, make it possible to distinguish this pathology among others and give it a national priority.

Understanding the causes that can induce the occurrence of dementia is important not only for health professionals, but also for those who formulate health policy. The increase in the number of patients with dementia influences the planning of national resources needed to manage the development of the system of providing medical and social services.

Although significant progress over the past 30 years has led to better understanding of this disease, there are still many questions that need to be addressed. Sometimes there are doubts that the ultimate goal can be achieved. There is the increasing amount of evidence that the life time of elderly people with dementia is lower than that of the same age group without dementia (Kua et al., 2014). There are also differences in the expected life time: people with severe mental disorders die an average 10-15 years earlier than the general population (World Health Organization, 2015b). However, there is potential for success, and experts in this field express optimism that the set goals are achievable (Snyder et al., 2015). Their optimism is based on the fact that the delay in the appearance of symptoms for only 5 years can reduce the cost of treatment of the disease by $50 \%$. Prevention is a promising strategy to stop or slow down progress in the spread of dementia, but the global epidemic requires support in terms of coordination, coordination and political support, at the international and national levels.

The political leaders, who, as a rule, have clear and evidence-based point of view on the preparation, influence and decision-making in the systemic response to dementia, are often the impulse for changes in health care systems and social assistance. These individuals involve innovative specialists to develop ideas, strategies or suggestions on how to structure and form preventive programs and carry out continuous care for dementia patients in a team of specialists with specific knowledge, experience (Broda et al., 2017).

Australia was the first country which made dementia a national health priority with the financial support plan (Skladzien et al., 2011). This experience has become a successful example of how coherent and well planned measures of policy can enable dementia to be considered as a national priority. As a result, the need to develop national plan became apparent for other countries as well, which gave stimulus to further action. By focusing more attention on prevention strategy, treatment and care or investing in research, each country uses its own approaches to provide national response and vision. But despite these differences, all these plans are ultimately aimed at improving the quality of life of people with dementia and their families.

Some countries have also focused on achieving their goals in the future by investing in research and health prevention (Skladzien et al., 2011). World leaders and politicians 
have taken note of the upcoming catastrophe, resulting in numerous national plans, international cooperation, and commitment to fund research. The Alzheimer's Association in Australia, Canada, France, the Netherlands, the United States and the United Kingdom reported that expenditures in the amount of $\$ 1$ million or more were targeted at research grants in 2011 (Wortmann, 2012).

Coordination activity is used widely in modern methods of public administration. Its development in some areas of healthcare has reached a level that coordination can be considered a method of government in the development and implementation of programs to combat dementia. The management covers the division of tasks, the use of new skills and mechanisms to achieve efficiency and effectiveness.

In the best case scenario, policy developers focus on strategic responses to issues related to government-level participation, cooperation and private sector partnerships, priorities and funding. At the various stages of development, implementation and funding, a longterm vision, a correct team, and the involvement of experts from the very beginning at all levels of government are formed clearly. Successful strategies also focus on the formation and maintenance of the strong communication program through communication networks, the exchange of information through common networks to support wider cooperation. It is important equally to foresee the stages of monitoring and evaluation of the measures taken.

Scientific, medical, political leaders and the public should work together, share experiences and resources, as it was done to address other global public health crises such as polio and the AIDS epidemic. According to scientists (Hodin, 2018; Ruger, 2005) and policy (The Guardian, 2018), several basic lessons that can help both the world community and individual countries to solve future threats can be gleaned from the experience of forming and implementing a model for countering HIV / AIDS. The key approaches that can be drawn from this model are: provoking social outrage to what is not enough to reduce the burden of dementia, reduce stigma and early diagnosis of the disease, combining efforts through coordination of measures and political pressure, which can strengthen research and acceptance strategic management measures. The development of national plans, based on the model of nationwide HIV / AIDS response or diabetes, is the best way to combat dementia at the country level (Wortmann, 2013).

\section{How to Put Theory into Practice?}

\subsection{First steps towards development of a national dementia plan in Ukraine}

Today, providing adequate and cost-effective assistance to the growing number of elderly people, their families and the community implies and requires cross-sectoral and interdisciplinary integration and collaboration. The development of community health care for the elderly is a global problem that has contributed to the creation of a number of programs and services, mainly in developed countries, but is increasingly being updated in developing countries.

Recognizing the need for a wider approach to the implementation of the local care system, there is a need to develop a model of coordinated medical and social services in the community targeted to the elderly. Dialogue between all interested parties, the exchange of ideas and thoughts significantly influences policy development, as well as 
the allocation of budget funds from the state and local budgets to consistent and interconnected programs of implementation and provision of comprehensive services.

Despite the fact that the Ministry of Health is the central point in Ukraine responsible for the development of state health policy, most of the issues concerning maintaining the health of the whole population are not only medical problems and therefore require an integrated approach with the involvement of several industries. In this situation, an important step towards addressing the priority issues is the development of the mechanism for the adoption of integrated management decisions, which consists in clear, understandable and effective agreement, coordination of actions of responsible participants. The coordination mechanism is being developed by the government, which should ensure the effectiveness of the state policy on preserving and improving the health of the population.

For implementation of a number of international commitments and decisions of the Government of Ukraine in the area of improving, increasing the efficiency and transparency of decision-making the interaction of executive authorities with civil society institutions is of vital importance. This interaction can take different forms depending on the goals set, the scale of interaction (national, regional and local level), the scope of authority of the subjects and the nature of the work performed.

The consideration of public opinion in the formation and implementation of state policy is a requirement of the present in promoting the executive authorities to build a democratic society. In order to facilitate the coordination of activities of executive authorities and to ensure the exercise of its powers, the Ministry of Health often uses such forms of interaction as the formation of joint advisory and expert bodies, councils, commissions, groups and other subsidiary bodies on matters within its competence. As a rule, such bodies are formed to ensure the exercise of powers of the Cabinet of Ministers of Ukraine, profile ministries and local state administrations and act on a voluntary basis on a collegial basis.

In most cases, the realization of the benefits requires the support of political leadership at the national and subnational (local) levels, as well as coordination between different levels of government and among them. This connectivity is essential for jointly developing strategies that differentiate between institutions and levels of government by envisaging and introducing joint financial mechanisms and creating the joint commitment needed to achieve sustainable outcomes. Achieving joint political leadership at the national and subnational levels can also be expressed in various ways to reflect specific cultural and political conditions at the local level.

Coordination work begins with the need to create an organizational structure to support, monitor and coordinate information on policy implementation and implementation of plans. This structure consists of phasing and coordination levels (Figure 4). The development and implementation of national dementia plans are based on three blocks that answer the question: What do we know about the problem? How do we solve the problem? What do we do to solve the problem? Understandable for all and interconnected sequential processes can play a key role in achieving these goals in the context of dementia. 
Figure 4. Proposed organizational structure for formation and implementation of the policy of counteraction to dementia in Ukraine

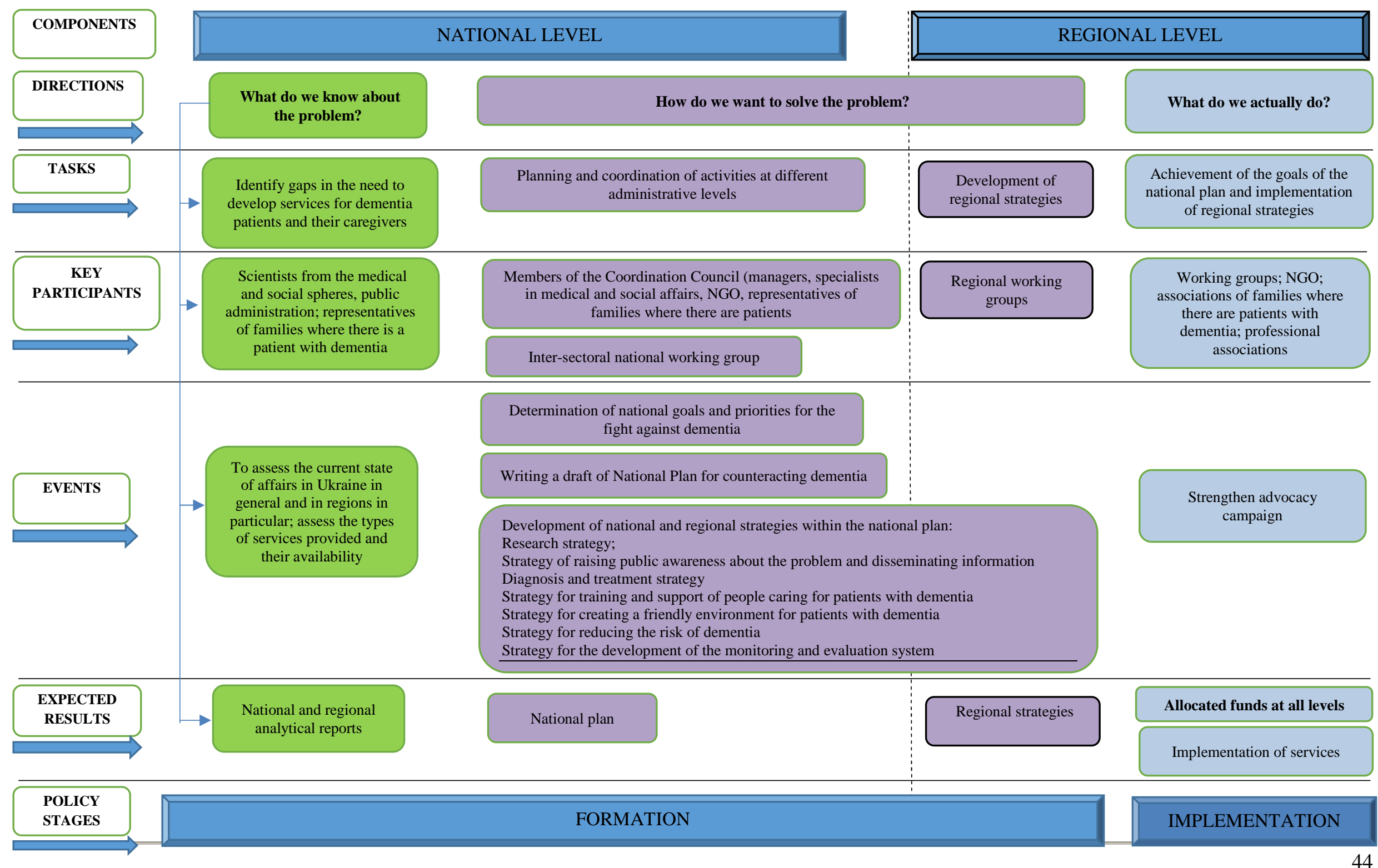

Source: Author's own representation 
While developing policies and plans for dementia, state agencies must harmonize all medical, social, legal and economic aspects of the disease. To this end, it is possible to foresee the formation of a Coordinating Council and inter-sectoral working groups that can develop national and regional plans. Those plans should be combined and implemented in cooperation with academic institutions, non-governmental organizations, professional organizations and government departments.

It is important to involve the public sector and professional organizations in advocacy campaigns aimed at medical and social systems to provide the full range of services that dementia and caregivers need. This includes empowerment and education among healthcare professionals and investment in health information systems.

\subsection{Intersectoral cooperation as a way to mainstream dementia care in Ukraine}

Caring for anyone with dementia is a very difficult task and many people carrying out such care experience physical and emotional stress (Wortmann, 2012). The organization of medical care and approaches to its provision in existing health systems in developing countries often do not meet the needs of chronically ill patients. To improve the results of these patients on the basis of the introduction of effective interventions, scientists suggest considering the following five approaches: use of evidence-based assistance and clearly planned; reorganization of existing systems and review of the role of service providers; improvement of the system of support of families caring for patients with dementia; increasing access to health services; and the dissemination of information about dementia in its various aspects (Wagner et al., 1996). Access to formal help for dementia remains a key issue for meeting the needs of services, improving the quality of life of people with dementia and reducing the financial burden associated with the course of the disease.

Discussions on plans for improving mental health at the national level relate to the provision of community-based services to support people with mental health problems, including integrating the mental health system into a primary care system. Health system reform is aimed at implementing national plans, achieving goals for the integration of quality care, health improvement, prevention services and reducing the burden of disease, emphasizing the need to rethink how best to provide the necessary services, to care for elderly people with dementia and their families. In addition, helping patients and carers with support and knowledge and reducing the inadequate use of health services can reduce health spending (Galvin et al., 2014).

The specificity of the disease to a certain extent limits the choice of patients in the amount of assistance they receive. These patients and caregivers prefer to receive services at the primary level than in specialized secondary-level institutions. Therefore, the development of services and the improvement of cooperation at the primary level can be a guarantee of success. However, in Ukraine there is an insufficient number of mental health services at the community level, as well as limited mental health services and support to other health professionals not specialized in mental health such as therapists and family doctors (World Bank Group, 2017).

Many countries have recognized and adopted policies to reduce the institutionalization of services and improve their quality through the implementation of home-care programs for patients with dementia. But this requires the development of appropriate support services for both dementia and their guardians. Guardians provide services that are as good, if not better, than those provided by professionals. However, the number of guardians receiving adequate support is minimal (Nolan and Badger, 2002). 
For the most part, those family members taking care of a person with dementia are often called invisible, second-rate patients (Brodaty and Donkin, 2009), but which are critical to the living standard of their persons under care. The family guardian, albeit sometimes positive, is generally negative, with a high level of burden and psychological morbidity, as well as social isolation, physical poor health and financial difficulties. Despite the volume of research and education in this area, people with dementia often suffer from neglecting of caregivers than from people they do not know.

Depression and stress among caregivers for patients with dementia are much higher than the general population, and this problem was neglected over the years. Since there is currently no therapy to help completely overcome the disease, disease prevention and family planning strategies are especially important. Given these circumstances, the question of how to help them and better support them gradually come to the front plan.

It is possible to help caregivers to cope with many problems, uncertainties and fears caused by the disease through early diagnosis, education and support. The development of the disease requires different types of support, so dementia and their families are in contact with a large number of health workers in a complex health system. In order to reduce the burden of caregivers and depression and to keep as long as possible and quality care of the patient in the home, it is inevitable to establish partnerships between health workers and the families who provide assistance.

Successful cooperation between the involved parties is obviously important, but studies focusing on interprofessional cooperation in the field of dementia treatment are scarce (Wortmann, 2013). An Australian study found that poor intersections between medical and non-medical or social services for the care of the elderly prevented attempts to obtain information on relevant support services (Stephan et al., 2015). One of the ways of improving the service for people with mental health problems in primary care may be to have one contact point with a healthcare worker or worker who may be affected by dementia or their caregivers; this person will negotiate and decide on how to better manage the situation. Strengthening links with primary health care is the most effective way to improve services, especially for the elderly and their carers.

Different forms of dementia were at different times classified as social or medical problems. The reality in most cases is that dementia is the condition that unites these two problems around them, and rarely when there is a separate one alone. Specialists should be aware that many physical illnesses can cause and exacerbate cognitive deficits. Older people with their health problems often have a set of social, medical and psychological problems that require special attention.

From the professionals in providing services to people with dementia, the development, types and quality of these services depend on. Collective care for this patient should be structured in this way as to maximize the skills and abilities of each member of the team. The models of joint assistance and care provide a pragmatic strategy for providing integrated medical and social services to patients, as well as their families. They are multidisciplinary interventions to improve patient care, through the provision of health care at the system level. The collective approach involves the use of probative arguments for medical decisions, the introduction of new clinical and information systems, and the involvement of patients and their family members or caregivers in the medical process. It is aimed at improving medical services, care, improving care, and effectively using community resources (Figure 5). Collaborative models also focus on joint decisionmaking through discussion between clinicians and patients (family guardians). By reaching agreement on a decision about the health impact that involves a lot of drug 
treatment, this model can best adapt the recommendations for improving and treating patients (World Health Organization, 2004). Joint decision-making allows clinicians to present and discuss treatment options, their associated risks and consequences, alternatives to traditional therapy, to report the database for these options and to assess their understanding from the perspective of the patient, family or guardian (Pot and Petrea, 2013).

\section{Figure 5. The advantages of cooperation between specialists of the primary level and specialists of specialized institutions}

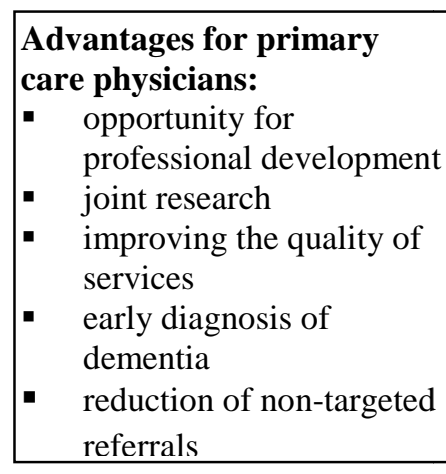

Advantages for caregivers:

- improvement of service coordination

- clear understanding of the role of each

- reducing stress and depression

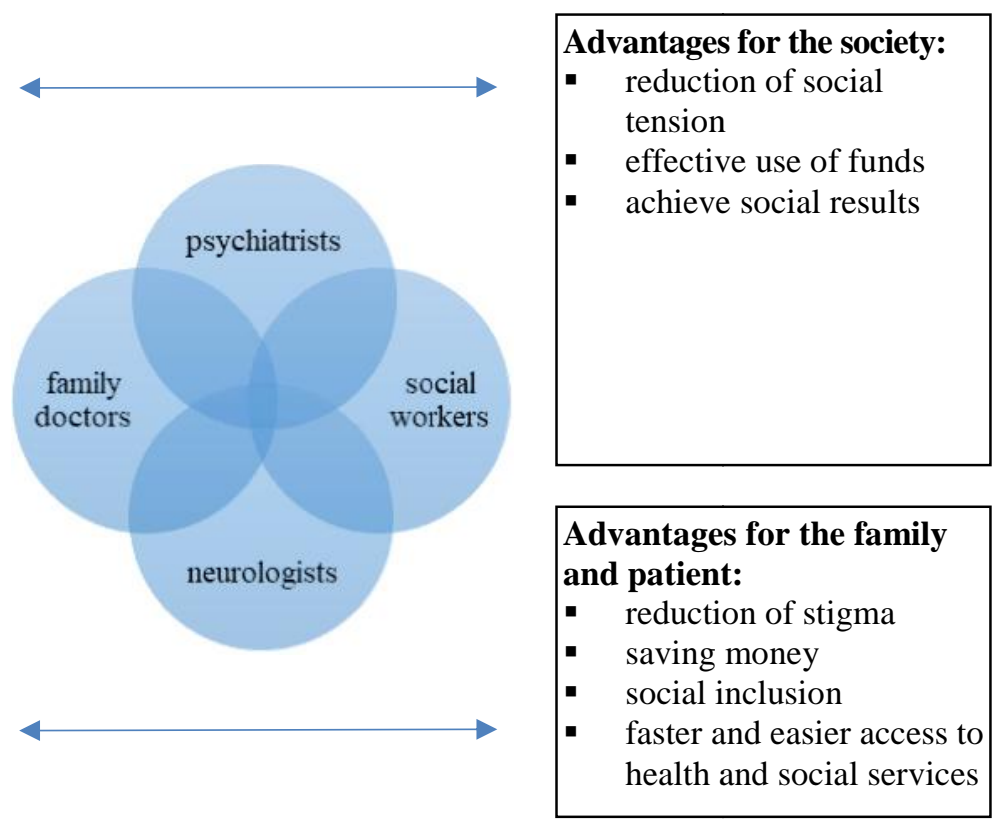

Advantages for the family and patient

- reduction of stigma

saving money

health and social services

Source: Author's own representation

The more often the attendants get together to investigate common problems, the more productive cooperation will be. The specialists can study a lot from each other, and sharing knowledge, experience and skills can be effective in improving services.

\section{Conclusions}

The problem of counteracting dementia in Ukraine is not yet a national priority, but conducting cross-sectoral studies can change fundamentally the situation. The comparative analysis of countries on several indicators available to us within the framework of this study gives grounds to believe that Ukraine will face the need for a detailed analysis of the problem of dementia.

There is no single best model for solving the problem of dementia, because each plan reflects a certain national context. But the approaches used in shaping the policy are part of the common. A coordinating approach that enables cooperation in the medical and social spheres allows defining priorities, as well as facilitating the expansion of access to necessary services for patients with dementia and caregivers.

Achievement of success in the complex situation of counteracting dementia can be achieved through the establishment of intersectoral cooperation at the primary level, where the provision of medical and social services is the closest to the patient and his 
carers. Coordinated collaboration on prevention, early diagnosis, effective treatment and care will increase access to services for those who need it.

\section{References:}

Alzheimer's Disease International (2015): Dementia statistics.

Broda, A., Bieber, A., Meyer, G., Hopper, L., Joyce, R., Irving et al. (2017): Perspectives of policy and political decision makers on access to formal dementia care: expert interviews in eight European countries. BMC Health Services Research (2017) 17:518.

Brodaty, H., Donkin, M. (2009): Family caregivers of people with dementia. Dialogues in Clinical Neuroscience 11(2): 217-228.

Dobriansky, P. J., Suzman, R. M., Hodes, R. J. (2007): Why population aging matters: A global perspective. National Institute on Aging, National Institutes of Health, US Department of Health and Human Services, US Department of State.

Galvin, J. E., Valois, L., Zweig, Y. (2014): Collaborative transdisciplinary team approach for dementia care. Neurodegenerative disease management 4(6), 455-469.

Garcia Ptacek, S., Kåreholt, I., Cermakova, P., Rizzuto, D., Religa, D., Eriksdotter, M. (2016) Causes of death according to death certificates in individuals with dementia: a cohort from the Swedish Dementia Registry. Journal of the American Geriatrics Society 64(11):e137-e142.

Hodin, M. (2018): Why Alzheimer's Is Our Children's Nightmare. Retrived from: https://www.huffingtonpost.com/michael-hodin/alzheimers-research-why-alzheimersnightmare_b_3052017.html.

Holtzman, D. M., John, C. M., Goate, A. (2011): Alzheimer's Disease: The Challenge of the Second Century. Science Translational Medicine 3(77): 77sr1.

Kua, E. H., Ho, E., Tan, H. H., Tsoi, C., Thng, C., Mahendran, R. (2014): The natural history of dementia. Psychogeriatrics 14(3), 196-201.

Ministry of Healthcare of Ukraine (2017): Schorichna dopivid' pro stan zdorov'ja naselennja, sanitarno-epidemichnu sytuaciju ta resultaty dijalnosti systemy ochorony zdorovja. 2016 [Annual report on the health status of the population, the sanitary and epidemiological situation and the results of the Ukrainian healthcare system's activities: 2016]. Retrived from : www.uiph.kiev.ua/d.

Nolan, P., Badger, F. (Eds.) (2002): Promoting collaboration in primary mental health care. Nelson Thornes.

Pinchyk I., Dudina Zh., Stapanova N. (2014): Mizhnarodnyj dosvid nadannja paliatyvmoji dopomohy chvorym na tjazhku demenziju [International experience of providing palliative care to patients with severe dementia] Retrived from: irbis-nbuv.gov.ua/cgi-bin/irbis_nbuv/cgiirbis_64.

Pot, A. M., Petrea, I. (2013): Bupa/ADI report 'Improving dementia care worldwide: Ideas and advice on developing and implementing a National Dementia Plan'. London: Bupa/ADI.

Rosow, K., Holzapfel, A., Karlawish, J.H., Baumgart, M., Bain, L. J., Khachaturian, A. S. (2011): Countrywide strategic plans on Alzheimer's disease: developing the framework for the international battle against Alzheimer's disease. Alzheimer's \& Demen.

Ruger, J. P. (2005): Democracy and health. Quarterly Journal of Medicine 98(4):299-304.

Skladzien, E., Bowditch, K., Rees, G. (2011): National Strategies to Address Dementia: A Report by Alzheimer's Australia. Alzheimer's Australia, Australia.

Snyder, H. M., Hendrix, J., Bain, L.J., Carrillo, M.C. (2015): Alzheimer's disease research in the context of the national plan to address Alzheimer's disease. Molecular aspects of medicine, 43, $16-24$

Stephan, A., Möhler, R., Renom-Guiteras, A., \& Meyer, G. (2015): Successful collaboration in dementia care from the perspectives of healthcare professionals and informal carers in Germany: results from a focus group study. BMC Health Services Research 15:208. 
The Guardian (2018): Dementia research: David Cameron calls for immediate action. Retrived from : https://www.theguardian.com/society/2014/jun/19/dementia-research-cameron-immediateaction.

The United Nations (2018): Sustainable Development Goals. Retrived from: https://sustainabledevelopment.un.org/?menu=1300.

University of Cambridge (2018): Dementia - a 21st century challenge. Retrieved from : https://www.cam.ac.uk/news/dementia-\%E2\%80\%93-a-21st-century-challenge.

Wagner, E. H., Austin, B. T., von Korff, M. (1996): Organizing care for patients with chronic illness. The Milbank Quarterly 511-544. Retrieved from :

https://www.ncbi.nlm.nih.gov/pubmed/8941260.

World Bank Group (2017): Psykhichne zdorovja na perechidnomy etapi: resultaty ozinuvannja ta rekomendazii dlja integrazii ochorony psykhichnoho zdorovija v systemy pervynnoji medychnoji dopomohy ta hromadki platformy v Ukraini [Mental health in transition: evaluation results and recommendations for the integration of mental health into the primary care system and public platforms in Ukraine]. Retrieved from : http://ipz.org.ua/wp-content/uploads/2018/01/MH-report-

World Health Organization (2004): A glossary of terms for community health care and services for older persons, WHO.

World Health Organization (2012): Dementia: a public health priority. World Health Organization.

World Health Organization (2015a): Call for action by the participants of the first WHO ministerial conference on global action against dementia. Geneva, 2015: 2.

World Health Organization (2015b): Meet Report on Excess Mortality in Persons with Severe Mental Disorders, WHO.

World Health Organization (2016): Governments commit to advancements in dementia research and care, WHO.

World Health Organization (2017a): Mental Health Atlas 2017, WHO.

World Health Organization (2017b): Global action plan on the public health response to dementia 2017-2025, WHO.

World Health Organization (2018): National health policies, strategies, plans. Retrieved from: http://www.who.int/nationalpolicies/nationalpolicies/en/.

World Life Expectancy (2018): World Health Rankings. Retrieved from:

http://www.worldlifeexpectancy.com/cause-of-death/alzheimers-dementia/by-country/female.

Wortmann, M. (2012): Dementia: a global health priority-highlights from an ADI and World Health Organization report. Alzheimer's research \& therapy 4(5):40.

Wortmann, M. (2013): Importance of national plans for Alzheimer's disease and dementia. Alzheimer's Research \& Therapy 5(5): 40. 